\title{
Late outcome of repair of congenital coronary artery fistulas—a word of caution
}

\author{
Sameh M. Said, MD, ${ }^{\mathrm{a}}$ Harold M. Burkhart, MD, ${ }^{\mathrm{a}}$ Hartzell V. Schaff, MD, ${ }^{\mathrm{a}}$ Heidi M. Connolly, MD, ${ }^{\mathrm{b}}$ \\ Sabrina D. Phillips, MD, ${ }^{\mathrm{b}}$ Rakesh M. Suri, MD, DPhil, ${ }^{\mathrm{a}}$ Ben Eidem, MD, ${ }^{\mathrm{c}}$ Charanjit S. Rihal, MD, ${ }^{\mathrm{b}}$ and \\ Joseph A. Dearani, MD
}

Objectives: We reviewed our experience with repair of congenital coronary artery fistulas.

\begin{abstract}
Methods: From June 1983 to December 2009, 46 patients (median age, 59 years; range, 1-84 years) underwent surgical repair. The presenting symptoms included angina in 16 patients $(35 \%)$, congestive heart failure in 11 $(24 \%)$, and bacterial endocarditis in $5(11 \%)$. Preoperatively, 9 patients $(20 \%)$ had at least moderate tricuspid regurgitation. Coronary artery dominance was right in 38 patients $(83 \%)$. Coronary artery aneurysms were found in 8 patients $(17 \%)$. The most common pattern was right coronary artery-to-coronary sinus fistula (18 patients, $39 \%)$; 11 patients had (23\%) more than 1 fistula. One patient had undergone previous coil embolization.
\end{abstract}

Results: Cardiopulmonary bypass was used in 39 patients $(85 \%)$, with extracardiac and intracardiac repair performed in $30(65 \%)$ and $16(35 \%)$, respectively. The most common associated procedures were coronary artery bypass in 13 patients $(28 \%)$. Early mortality occurred in 1 patient $(2 \%)$. Postoperative myocardial infarction occurred in 5 patients $(11 \%)$; 4 of these patients underwent simple ligation or division of their fistulas. The mean follow-up was $6 \pm 5.8$ years (maximum, 22 years). Late mortality occurred in 11 patients $(24 \%)$. Two patients underwent reoperation for severe tricuspid regurgitation. Survival was significantly reduced compared with the age- and gender-matched population $(P=.03)$. Residual fistulas were detected in 3 patients $(6 \%)$, with no reintervention needed.

Conclusions: Perioperative myocardial infarction is an important complication of ligation of coronary artery fistulas and can contribute to reduced late survival. The tricuspid valve should be evaluated carefully at repair because of the relatively high rate of residual regurgitation in survivors. (J Thorac Cardiovasc Surg 2013; 145:455-60)

Coronary artery fistulas (CAFs) represent abnormal communications between a coronary artery (CA) and other cardiovascular structures. These abnormal communications can be to a cardiac chamber, coronary sinus (CS), superior vena cava, or pulmonary artery. ${ }^{1}$ CAFs are relatively uncommon, with the incidence reported to be $0.1 \%$ to $0.2 \%$ of all patients who undergo selective coronary angiography. ${ }^{2}$ These communications can be congenital or acquired. Congenital CAFs can be isolated or complex depending on whether they are associated with other congenital heart diseases. Complex CAFs can be found in hypoplastic left heart syndrome ${ }^{3}$ and in pulmonary atresia with intact ventricular septum, ${ }^{4}$ but these have different management strategies

From the Divisions of Cardiovascular Surgery, ${ }^{\mathrm{a}}$ Cardiovascular Diseases, ${ }^{\mathrm{b}}$ and Pediatric Cardiology, ${ }^{\mathrm{c}}$ Mayo Clinic, Rochester, Minn.

Disclosures: Authors have nothing to disclose with regard to commercial support.

Read at the 38th Annual Meeting of The Western Thoracic Surgical Association, Maui, Hawaii, June 27-30, 2012.

Received for publication June 27, 2012; revisions received Oct 16, 2012; accepted for publication Nov 9, 2012; available ahead of print Dec 6, 2012

Address for reprints: Harold M. Burkhart, MD, Division of Cardiovascular Surgery, Mayo Clinic, 200 First St, Southwest, Rochester, MN 55905 (E-mail: burkhart. harold@mayo.edu).

$0022-5223 / \$ 36.00$

Copyright $\odot 2013$ by The American Association for Thoracic Surgery

http://dx.doi.org/10.1016/j.jtcvs.2012.11.028 than other types of congenital CAFs. The overall management of such anomalies has been controversial; with 2 main available options: surgical repair or catheter embolization. We reviewed our experience with surgical treatment of CAFs.

\section{METHODS \\ Patient Population}

From June 1983 to December 2009, 46 patients with congenital CAFs underwent surgical repair at our institution. The mean age at repair was $56.2 \pm 18$ years (range, 1-84 years). Of the 46 patients, 22 were male $(48 \%)$ and 24 were female $(52 \%)$, including 2 children $(4 \%)$ CAFs associated with hypoplastic left heart syndrome or pulmonary atresia with an intact ventricular septum were excluded from the present cohort During the same period, 26 patients with isolated CAF underwent transcatheter coil embolization. The Mayo Clinic and Foundation institutional review board approved the present retrospective review.

\section{Preoperative Data}

The presence of symptoms or signs of right ventricular volume overload were the main indications for surgery. Of the 46 patients, $7(15 \%)$ were asymptomatic. The most common symptoms were exertional dyspnea in 28 patients $(61 \%)$ and angina in 16 patients $(35 \%)$. Atrial fibrillation was present in 10 patients $(22 \%)$. Preoperatively, 16 patients were in New York Heart Association class III or IV. Also, 5 patients (11\%) had a history of bacterial endocarditis, and 4 had undergone previous cardiac surgery, including ventricular septal defect closure in 2 and mitral valve repair in 2 . 


$$
\begin{aligned}
& \text { Abbreviations and Acronyms } \\
& \begin{aligned}
\mathrm{CA} & =\text { coronary artery } \\
\mathrm{CAF} & =\text { coronary artery fistula } \\
\mathrm{CPB} & =\text { cardiopulmonary bypass } \\
\mathrm{CS} & =\text { coronary sinus } \\
\mathrm{MI} & =\text { myocardial infarction } \\
\mathrm{RCA} & =\text { right coronary artery } \\
\mathrm{TV} & =\text { tricuspid valve }
\end{aligned}
\end{aligned}
$$

Preoperative transthoracic echocardiography showed the presence of wall motion abnormalities in 10 patients $(22 \%)$, right ventricular dilatation in $10(22 \%)$, and at least moderate tricuspid valve (TV) regurgitation in $9(20 \%)$.

CAFs were diagnosed during cardiac catheterization in 24 patients $(52 \%)$. The CA dominance was right, left, and codominant in 38 $(83 \%), 1(2 \%)$, and $2(4 \%)$ patients, respectively. Nine patients $(20 \%)$ had significant associated CA disease. CA aneurysms were identified in 8 patients $(17 \%)$.

\section{Surgical Technique}

The surgical procedure was performed through a standard median sternotomy. Cardiopulmonary bypass (CPB) was used in 39 patients $(85 \%)$, and ligation of the CAF was performed epicardially without $\mathrm{CPB}$ in 7 patients $(15 \%)$.

Multiple CAFs were present in 11 patients (23\%). The most common site of origin (Table 1) was the right coronary artery (RCA) in 22 patients (48\%), and the most common site of drainage (Table 1) was the CS in 18 patients $(39 \%$; Figure 1). Extracardiac repair was performed in 33 patients ( $72 \%)$, intracardiac repair in 13 patients $(28 \%)$, and combined extra- and intracardiac repairs in the remaining 3 patients $(6 \%$; Table 2 and Figures 2 and 3). The different types of CAF identified among our series are listed in Table 3.

The most common associated procedures were $\mathrm{CA}$ bypass in 13 patients

\begin{tabular}{|c|c|}
\hline Variable & n $(\%)$ \\
\hline \multicolumn{2}{|l|}{ Site of origin } \\
\hline RCA & $22(48)$ \\
\hline $\mathrm{Cx}$ & $13(28)$ \\
\hline LAD & $12(26)$ \\
\hline LMCA & $3(7)$ \\
\hline \multicolumn{2}{|l|}{ Drainage site } \\
\hline CS & $18(39)$ \\
\hline $\mathrm{PA}$ & $12(26)$ \\
\hline RV & $7(15)$ \\
\hline RA & $5(11)$ \\
\hline SVC & $2(4)$ \\
\hline Mediastinal veins & $2(4)$ \\
\hline
\end{tabular}
$(28 \%)$ and patent foramen ovale closure in $7(15 \%)$. TV surgery was performed in 6 patients (13\%), including repair in 4 and replacement in 2 .

\section{Follow-up}

The mean follow-up duration from surgery to the last follow-up visit was $6 \pm 5.8$ years (maximum, 22 years). Follow-up echocardiographic data and electrocardiograms were available for 33 patients $(72 \%)$.

TABLE 1. Sites of origin and drainage of coronary artery fistulas

$R C A$, Right coronary artery; $C x$, circumflex coronary artery; $L A D$, left anterior descending artery; $L M C A$, left main coronary artery; $C S$, coronary sinus; $P A$, pulmonary artery; $R V$, right ventricle; $R A$, right atrium; $S V C$, superior vena cava.

\section{Statistical Analysis}

The descriptive statistics for categorical variables are reported as the frequency and percentages and continuous variables as the mean \pm standard deviation or median and range, as appropriate. The KaplanMeier method was used to draw the survival curves and calculate the 5- and 10-year survival statistics. The log-rank test was used to compare the difference in survival between the different groups. All statistical tests were 2 -sided, with the $\alpha$ level set at 0.05 for statistical significance.

\section{RESULTS}

One early mortality $(2 \%)$ occurred. This was a 60 -yearold woman with a large RCA-CS fistula that was ligated epicardially without CA bypass. Five days later, the patient experienced sudden cardiac arrest owing to a massive myocardial infarction (MI) with free wall rupture and secondary pericardial tamponade. She was resuscitated and was taken emergently to the operating room where the ventricular rupture was repaired. However, the patient sustained severe anoxic brain injury, and support was withdrawn 3 days later. Early reoperation was required in 2 patients $(4 \%)$ because of postoperative bleeding.

Perioperative MI occurred in 3 patients $(6.5 \%)$, including the early mortality previously discussed. The second patient was a 70-year-old man with a large RCA to right atrial fistula and associated giant RCA aneurysm. Excision of the proximal portion of the RCA was performed, and a segment of saphenous vein was used as an interposition graft. Postoperatively, he developed right ventricular MI, which manifested as new ischemic electrocardiographic changes, with subsequent sudden cardiac arrest due to ventricular fibrillation. He was adequately resuscitated but had severe depression in his right ventricular function. The last patient was a 41-year-old woman with a large RCA-CS fistula and associated RCA aneurysm. The proximal portion of the RCA was excised, and the fistula was ligated; however, no CA bypass was performed. Postoperatively, she experienced an inferior wall MI with no major consequences. None of these patients received any anticoagulation after surgery for their CAF.

The long-term survival was $93 \%, 74 \%$, and $68 \%$ at 1,5 , and 15 years, respectively (Figure $4, A$ ). No difference was found in survival between those who were younger than 60 years old and those who were older $(P=.13)$. The overall survival of patients with congenital CAF was significantly lower than that of a matched Minnesotan white population $(P=.031$; Figure $4, B)$.

Late mortality occurred in 11 patients $(24 \%)$ and was from noncardiac causes in 10 . The etiology of death was unknown in 7 patients, terminal malignancy in 1, multisystem organ failure from advanced bowel ischemia in 1, suicide in 1 , and acute $\mathrm{MI}$ in 1 . The last patient was a 57 -year-old woman with a large RCA-CS fistula and a large RCA aneurysm. Epicardial ligation of the fistula was performed, and she was dismissed with no early postoperative events and no anticoagulation. However, 7 months later, she had 


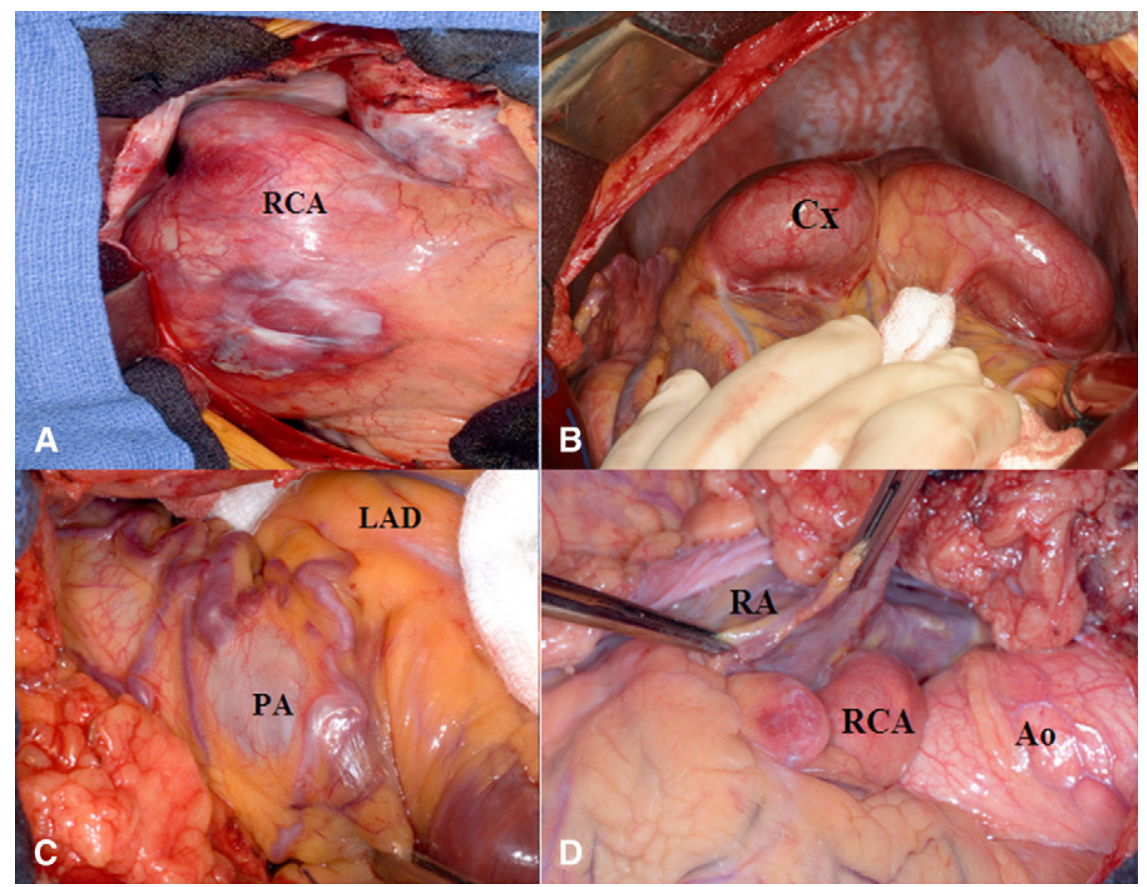

FIGURE 1. Intraoperative photographs showing some congenital coronary artery fistula types encountered in our series. A, Right coronary artery ( $R C A)$ aneurysm in patient with RCA-to-coronary sinus fistula; $\mathrm{B}$, large dilated and tortuous circumflex $(C x)$ coronary artery in patient with $\mathrm{Cx}$-to-coronary sinus fistula; $\mathrm{C}$, left anterior descending $(L A D)$-to-pulmonary artery $(P A)$ fistula with multiple collaterals visualized on anterior surface of PA; and D, dilated RCA in patient with RCA-to-right atrial fistula. RA, Right atrium; Ao, aorta.

experienced sudden cardiac arrest due to a massive MI and died despite resuscitative efforts.

Late MI occurred in 2 patients. These included the late death previously discussed. The second patient was a 34-year-old woman with an RCA-CS fistula. She had a large $\mathrm{RCA}$, and the fistula was ligated using a transcoronary approach. She was prescribed warfarin for 6 weeks postoperatively. However, after discontinuation of the anticoagulation, she experienced a sudden inferior wall MI and was found to have a $100 \%$ occlusion of her RCA.

Late reoperation was required in 3 patients $(6.5 \%)$. The first patient was a 41-year-old woman who underwent mitral and TV repairs, in addition to a single CA bypass graft to the RCA 2 years after ligation of her large RCA-CS fistula. The second patient was a 63-year-old woman who underwent ligation and division of a left main coronary artery-to-right atrial fistula. Nine years later, she underwent repeat median sternotomy for TV replacement secondary to severe tricuspid regurgitation. Another patient, a 75-yearold woman who had undergone ligation of RCA-CS fistula with TV replacement underwent repeat median sternotomy for replacement of both aortic and mitral valves secondary to severe regurgitation.

One patient $(2 \%)$ developed recurrent coronary fistulas during the follow-up period. The patient was a 41-yearold woman who underwent excision of a large RCA-CS fistula. The initial echocardiogram did not show any evidence of persistent fistulous communication. Two years later, her echocardiogram showed CS dilatation with persistent systolic and diastolic flow suggestive of a residual communication between the RCA and CS not requiring intervention. Residual fistulas were identified in 3 patients $(6 \%)$; however, they were not hemodynamically significant, and no interventions were required.

\section{DISCUSSION}

The first report of a CAF by Krause appeared in $1865,{ }^{6}$ and the first successful surgical correction was by Biorck and Crafoord in $1947 . .^{5}$ A limited number of cases have been reported in published studies, and it has been reported

TABLE 2. Repair techniques for different coronary artery fistulas

\begin{tabular}{lc}
\hline \multicolumn{1}{c}{ Variable } & $\mathbf{n}(\%)$ \\
\hline Extracardiac repair & \\
Direct epicardial ligation & $22(48)$ \\
CA ligation close to fistula entry point & $6(13)$ \\
Transcoronary closure & $4(9)$ \\
RCA excision & $2(4)$ \\
CA aneurysm excision & $1(2)$ \\
Intracardiac repair & \\
Transpulmonary closure & $7(15)$ \\
Transatrial closure & $3(6)$ \\
Transcoronary sinus repair & $2(4)$ \\
\hline
\end{tabular}

$C A$, Coronary artery; $R C A$, right coronary artery. 

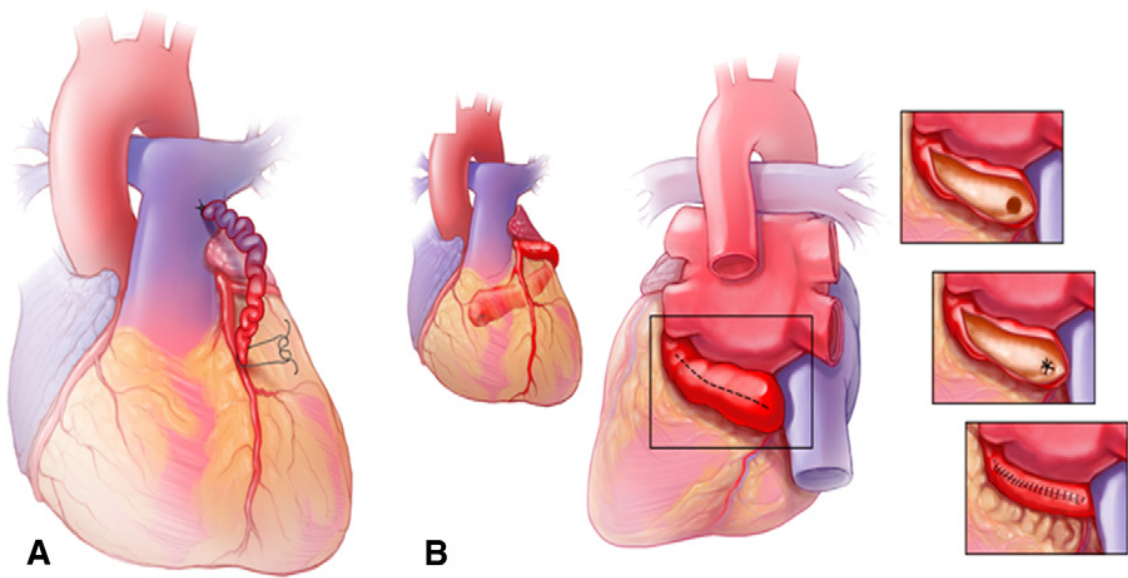

FIGURE 2. Illustrations of some surgical techniques used in repairing coronary fistulas. A, Direct epicardial ligation of fistula while preserving distal coronary artery flow; and B, transcoronary approach for closure of fistula, which is possible in the case of a large dilated coronary artery.

that $0.1 \%$ to $0.2 \%$ of all patients who undergo selective coronary arterial angiography are diagnosed with a CAF. ${ }^{6}$

Two main treatment options are available, surgical and or transcatheter closure. Surgical repair can be performed with or without $\mathrm{CPB}$ and with or without concomitant CA bypass. Multiple surgical techniques have been applied, including epicardial ligation with or without actual division of the fistula or closure by a transcoronary, through a cardiac chamber (transcameral), or transpulmonary approach.

The classification of CAFs that was introduced by Sakakibara and colleagues ${ }^{7}$ might help in choosing the optimal surgical approach. They classified CAFs angiographically into proximal or distal types. In the proximal type (type A), the proximal segment of the coronary artery is dilated to the fistula, with the normal distal portion, which usually occurs when the CAF is oriented in a side-to-side fashion. In the distal type (type B), the entire length of the coronary artery is dilated, with the fistula more oriented in an endto-side fashion. Epicardial ligation of the fistula, while maintaining normal coronary flow, or ligation of the CA proximal and distal to the fistula with or without concomitant CA bypass might be a reasonable option for type A fistula, although transcoronary or transcameral closure might be suited best for type B CAFs. ${ }^{8}$

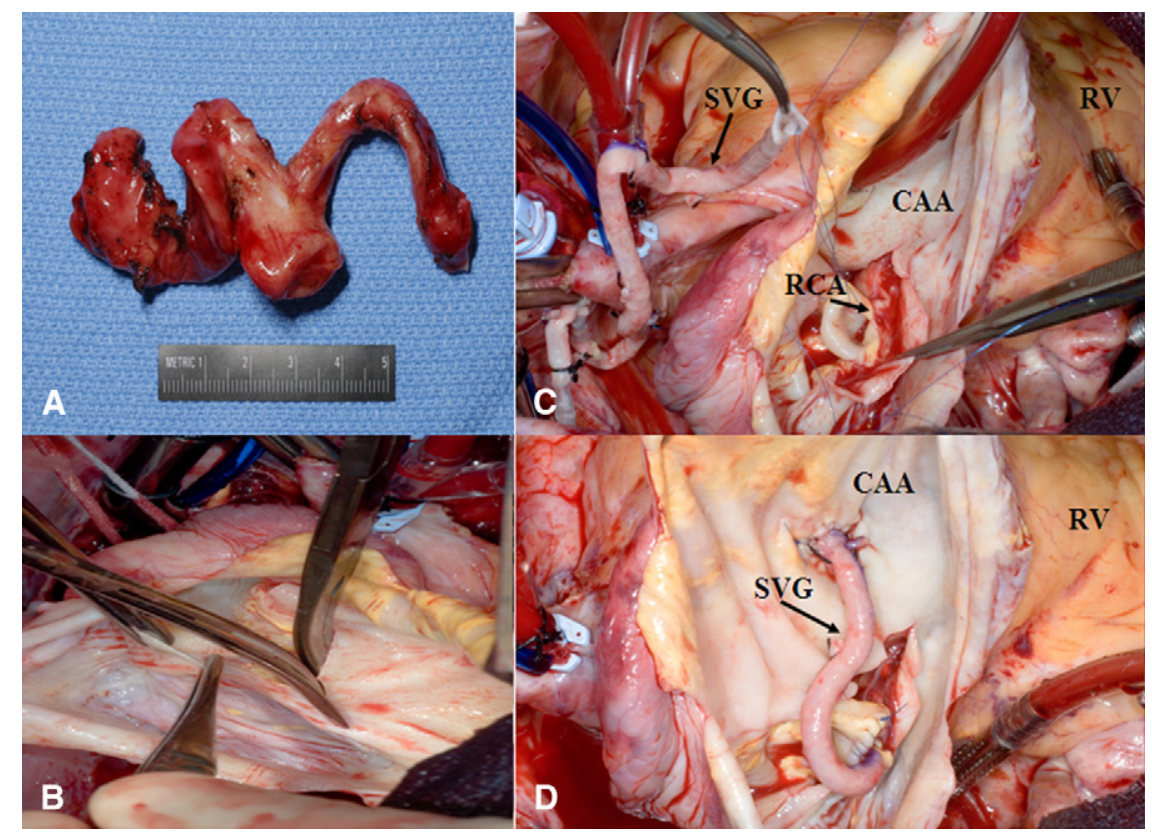

FIGURE 3. Intraoperative photographs showing A, excised portion of right coronary artery $(R C A)$ with associated aneurysm. In 1 patient with large RCA aneurysm, the aneurysm was opened, B, the excess wall was excised, C, a segment of the saphenous vein was used as an interposition graft to maintain flow to $\mathrm{D}$, the distal portion of the RCA. $S V G$, Saphenous vein graft; $C A A$, coronary artery aneurysm; $R V$, right ventricle. 
TABLE 3. Various coronary artery fistulas identified

\begin{tabular}{lr}
\hline Coronary artery fistula & n $(\%)$ \\
\hline RCA-CS & $11(24)$ \\
LAD-PA & $9(20)$ \\
CX-CS & $8(17)$ \\
RCA-RV & $6(13)$ \\
CX-RV & $2(4)$ \\
LMCA-RA & $2(4)$ \\
RCA-RA & $2(4)$ \\
CX-PA & $1(2)$ \\
CX-SVC & $1(2)$ \\
CX-mediastinal veins & $1(2)$ \\
RCA-mediastinal veins & $1(2)$ \\
LMCA-PA & $1(2)$ \\
RCA-PA & $1(2)$ \\
LAD-RA & $1(2)$ \\
RCA-SVC & $1(2)$ \\
\hline
\end{tabular}

$R C A$, Right coronary artery; $C S$, coronary sinus; $L A D$, left anterior descending coronary artery; $P A$, pulmonary artery; $C x$, circumflex coronary artery; $R V$, right ventricle; $L M C A$, left main coronary artery; $R A$, right atrium; $S V C$, superior vena cava.

In the present series, 22 patients (48\%) underwent direct epicardial ligation of their fistulas, transcoronary fistula closure was performed in 4 patients $(9 \%)$, and a transatrial approach was used in 3 patients $(6 \%)$. The different repair techniques used in our series are listed in Table 2. Closure of the fistula can be done in many cases without the use of $\mathrm{CPB}$, unless they are inaccessible, associated with a $\mathrm{CA}$ aneurysm that needs to be addressed, or in the presence of concomitant cardiac pathologic features requiring repair. ${ }^{9}$ We used CPB in 39 patients $(85 \%)$ because of either the proximal origin of the fistula or an inability to identify the course with certainty. The associated CA aneurysm can be isolated or resected, and the distal coronary flow can be maintained with either an interposition graft or a concomitant CA bypass graft. ${ }^{10}$ In the present series, CA aneurysms were present in 8 patients $(17 \%)$. The aneurysm was excised in 1 patient and a segment of saphenous vein was used as an interposition graft to maintain distal flow. In 1 patient with an RCA-CS fistula, the aneurysm was distal to the fistulous communication, and it was excised, and the RCA was ligated proximally. Before considering CA ligation, it is critical to consider the $\mathrm{CA}$ dominance and to exclude the presence of important distal coronary branches that contribute to the myocardium. This information is typically obtained from coronary angiography, which is a part of our preoperative workup. More recently, we have used cardiac computed tomography with 3-dimensional reconstruction to confirm the fistulous and $\mathrm{CA}$ anatomy. Intraoperatively, we consider clamping the CA temporarily in multiple locations to determine whether any ST-segment changes occur that might indicate the need for maintaining distal coronary arterial flow. In addition, a hand-held Doppler probe can be used to detect the location of the fistula and identify important branches. Then, the decision is whether to use either an interposition graft or a concomitant CA bypass graft. In the third and fourth patients who had an RCA to the right ventricular fistula and an RCA to the right atrial fistula, respectively, the fistula and proximal RCA were ligated, and concomitant CA bypass grafting was performed to the posterior descending branch. In the remaining 4 patients, the fistulas were ligated, and aneurysmorrhaphy was performed, thus maintaining distal coronary arterial flow.

Transcatheter closure of the CAF is an alternative option for $\mathrm{CAF}$ treatment, and various occlusion techniques have been described, including occlusion coils, ${ }^{11}$ vascular plugs, ${ }^{12}$ or covered stents. ${ }^{13}$ Large and wide fistulas, multiple fistulas, or other concomitant cardiac pathologic entities represent the main contraindications to the transcatheter approach. ${ }^{14}$ In a previous study from our institution, ${ }^{15}$ percutaneous embolization was performed in 6 patients; the technique was determined by the feasible anatomy, an ability to cannulate the fistula, and the proximity of the coronary branches to the optimal occlusion site. No mortality or periprocedural myocardial infraction occurred in this subgroup. Two patients had residual but insignificant fistulas with no additional intervention needed. In the study by Armsby and colleagues, ${ }^{16}$ they reported 33 patients at 35 procedures who underwent transcatheter closure of their CAF. Complete occlusion was achieved in 27 patients $(82 \%)$. Transient ST-segment changes were observed in 5 patients; however, no deaths or long-term morbidity were observed.

Transient ST-segment changes have been noted after closure of CAFs, whether transcatheter or surgical; however,
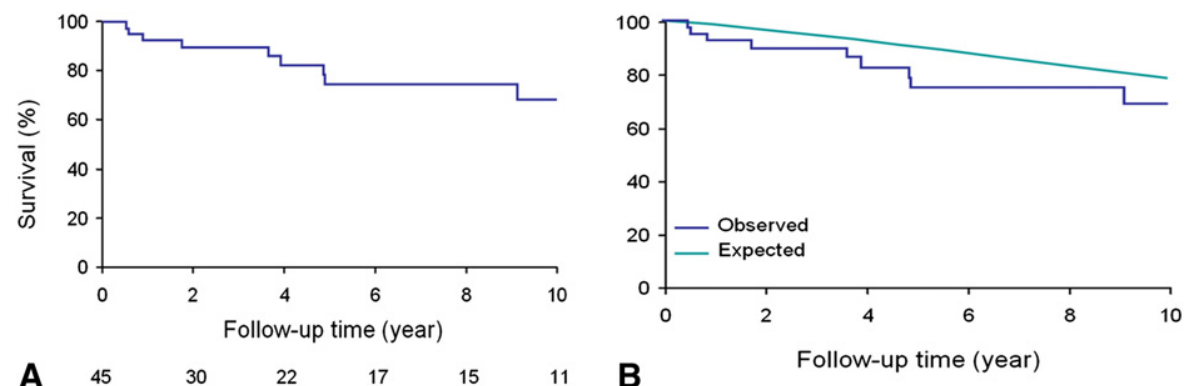

$$
\begin{array}{lllllll}
\text { A } & 45 & 30 & 22 & 17 & 15 & 11
\end{array}
$$

FIGURE 4. Kaplan-Meier survival curves. A, Overall survival of patients in study and B, survival compared with age- and gender-matched population. 
the true incidence of periprocedural or late MI is unknown. In the study reported by Cheung et al, ${ }^{17} 41$ patients who underwent surgical repair of CAFs were evaluated. External plication or division of the fistula was performed in 18 patients, because no ischemic response was demonstrated after temporary occlusion of the fistula. In the remaining 23 patients, $\mathrm{CPB}$ was used, with intracardiac repair of the fistula. Three patients had evidence of ischemic changes on the electrocardiogram, in addition to elevation of their cardiac enzymes. We observed perioperative $\mathrm{MI}$ in 3 of our patients $(6.5 \%)$, and late MI was documented in 2 other patients. The common factors noted were the presence of a large and significant fistulous communication and dilated or aneurysmal CA. The infarction occurred in the distribution of the involved CA. The occurrence of early postoperative MI can be explained by the removal of important coronary arterial branches in the case of ligation or excision of the fistula without maintaining normal distal coronary artery flow. Late MI can be explained by the occurrence of late native coronary artery thrombosis, which is well documented in previous studies. ${ }^{18}$ This is not uncommon in large CAFs with associated aneurysms owing to the relatively low flow in the dilated CA. Consideration for anticoagulation is warranted in such situations. We typically use a period of anticoagulation with warfarin for 3 to 6 months in those cases.

In a recent study reported by Valente et al, ${ }^{19} 44$ patients with congenital CAFs underwent transcatheter closure and 20 patients underwent surgical repair. The major complications in that study, including MI, occurred in 11 patients $(15 \%)$. In the transcatheter group, ST-segment changes were noted in 5 patients, and 7 patients in the surgical group experienced a MI. Two patients had angina with documented intracoronary thrombus, including one with thrombus formation despite warfarin anticoagulation and a therapeutic international normalized ratio 4 years after surgical repair. The investigators identified drainage of the CAF into the $\mathrm{CS}$ as the single angiographic feature that was significantly associated with the occurrence of major complications $(P<$ $.001)$. The CS was the site of drainage in 4 of 5 patients who developed MI in our series. We had 1 patient who experienced late MI despite anticoagulation with warfarin.

TV regurgitation secondary to a dilated annulus and in the presence of right ventricular enlargement is not uncommon in lesions with significant volume overload, such as in congenital CAF. Special attention to the TV in these cases and consideration for TV repair are warranted. In our series, TV surgery was needed in 6 patients $(13 \%)$, with repair in 4 and replacement in 2, respectively. Two patients underwent late reoperation for $\mathrm{TV}$ regurgitation.

\section{CONCLUSIONS}

MI after surgical ligation of CAF is a real concern and can occur early or late after surgical intervention. Careful evaluation of all large fistulas, especially those draining into the CS, is critical before considering simple ligation. Special attention to CA dominance and preservation of important distal coronary arterial branches is warranted. The TV should be thoroughly evaluated with a low threshold for valvuloplasty to avoid late reoperation.

\section{References}

1. Mavroudis C, Backer CL, Rocchini AP, Muster AJ, Gevitz M. Coronary artery fistulas in infants and children: a surgical review and discussion of coil embolization. Ann Thorac Surg. 1997;63:1235-42.

2. Said SA, El Gamal MI, van der Werf T. Coronary arteriovenous fistulas: collective review and management of six new cases-changing etiology, presentation, and treatment strategy. Clin Cardiol. 1997;20:748-52.

3. Baffa JM, Chen SL, Guttenberg ME, Norwood WI, Weinberg PM. Coronary artery abnormalities and right ventricular histology in hypoplastic left heart syndrome. J Am Coll Cardiol. 1993;20:350-8.

4. Calder AL, Co EE, Sage MD. Coronary arterial abnormalities in pulmonary atresia with intact ventricular septum. Am J Cardiol. 1987;59:436-42.

5. Fernandes ED, Kadivar H, Hallman FI, Reul GJ, Ott DA, Cooley DA. Congenital malformations of the coronary arteries: the Texas Heart Institute experience. Ann Thorac Surg. 1992;54:732-40.

6. Said SM, Dearani JA, Burkhart HM, Schaff HV. Surgical management of congenital coronary arterial anomalies in adults. Cardiol Young. 2010; 20(Suppl 3):68-85.

7. Sakakibara S, Yokoyama M, Takao A, Nogi M, Gomi H. Coronary arteriovenous fistula: nine operated cases. Am Heart J. 1966;72:307-14.

8. Dimitrakakis G, Otto von Oppell U. eComment: surgical treatment of coronary arteriovenous fistulas. Interact Cardiovasc Thorac Surg. 2011;13:674-5.

9. Mahesh B, Navaratnarajah M, Mensah K, Amrani M. Treatment of high-output coronary artery fistula by off-pump coronary artery bypass grafting and ligation of fistula. Interact Cardiovasc Thorac Surg. 2009;9:124-6.

10. Holinski S, Dohmen PM, Lembcke A, Konertz W. Surgical management of multiple coronary artery aneurysms, including the giant form. Tex Heart Inst J. 2009; 36:238-40.

11. Perry SB, Rome J, Keane JF, Baim DS, Lock JE. Transcatheter closure of coronary artery fistulas. J Am Coll Cardiol. 1992;20:205-9.

12. Fischer G, Apostolopoulou SC, Rammos S, Kiaffas M, Kramer HH. Transcatheter closure of coronary arterial fistulas using the new Amplatzer vascular plug. Cardiol Young. 2007; 17:283-7.

13. Karagoz T, Celiker A, Cil B, Cekirge S. Transcatheter embolization of a coronary fistula originating from the left anterior descending artery by using $N$-butyl 2-cyanoacrylate. Cardiovasc Intervent Radiol. 2004;27:663-5.

14. Mangukia CV. Coronary artery fistula. Ann Thorac Surg. 2012;93:2084-92.

15. Abdelmoneim SS, Mookadam F, Moustafa S, Zehr KJ, Mookadam M, Maalouf JF, et al. Coronary artery fistula: single-center experience spanning 17 years. J Interv Cardiol. 2007;20:265-74.

16. Armsby LR, Keane JF, Sherwood MC, Forbess JM, Perry SB, Lock JE. Management of coronary artery fistulae. J Am Coll Cardiol. 2002;39:1026-32.

17. Cheung DL, Au WK, Cheung HH, Chiu CS, Lee WT. Coronary artery fistulas: long-term results of surgical correction. Ann Thorac Surg. 2001;71: 190-5.

18. Gowda ST, Latson LA, Kutty S, Prieto LR. Intermediate to long-term outcome following congenital coronary artery fistulae closure with focus on thrombus formation. Am J Cardiol. 2011;107:302-8.

19. Valente AM, Lock JE, Gauvreau K, Rodriguez-Huertas E, Joyce C, Armsby L, et al. Predictors of long-term adverse outcomes in patients with congenital coronary artery fistulae. Circ Cardiovasc Interv. 2010;3:134-9. 